\title{
MicroRNAs in colorectal carcinoma - from pathogenesis to therapy
}

Yudan Chi and Dongming Zhou*

\begin{abstract}
Background: Acting as inflammatory mediators, tumor oncogenes or suppressors, microRNAs are involved in cell survival, death, epithelial-mesenchymal transition and metastasis, etc. Investigating the communication between microRNAs and tumorigenesis is critical to our understanding of the pathogenesis of multiple disease states.

Main body: Currently, colorectal carcinoma (CRC), one of the most common malignancies worldwide, has a poor prognosis due to lack of an effective therapeutic option. Increasing evidence has identified altered profiles and regulatory potential of microRNAs in conditions related to environmentally-caused colorectal inflammation and colitis-associated cancer. Many studies have shed light on a more thorough understanding of the function and distribution of microRNAs in CRC initiation and emergence. However, the molecular mechanisms by which microRNAs modulate cellular processes still need to be further elucidated and may offer a foundation for evaluating microRNA-based therapeutic potential for CRC in both animal models and clinical trials.
\end{abstract}

Conclusion: In this review, the roles and mechanisms of microRNAs involved in CRC from pathogenesis to therapy are summarized and discussed, which may provide more useful hints for CRC prevention and therapy.

Keywords: MicroRNA, Colorectal carcinoma, Pathogenesis, Diagnosis, Cancer therapy

\section{Introduction}

MicroRNAs (miRNAs) are endogenously expressed noncoding RNAs, 18-25 nucleotides in length, which silence target mRNAs by mediating translational repression [1-4]. The miRNA biogenesis pathway includes multiple steps. Initially, pri-miRNAs (primary-miRNAs) containing a hairpin structure are transcribed by the RNA polymerase II which is responsible for mRNA expression. These primiRNAs are then cleaved into 60-70 base pairs long precursor miRNAs (pre-miRNAs) by the RNase III Drosha. Then, the pre-miRNAs are transported from the nucleus to the cytoplasm by Exportin-5/RanGTP and further processed by Dicer to form a short double-stranded miRNA duplex. Generally, only one strand of this miRNA duplex is degraded, while the other strand is released as a mature miRNA. Subsequently, this miRNA is integrated into RISC (RNA-induced Silencing Complex) to trigger degradation and translational repression of the target mRNA $[5,6]$.

\footnotetext{
* Correspondence: dmzhou@sibs.ac.cn
Vaccine Research Center, Key Laboratory of Molecular Virology \&

* Correspondence: dmzhou@sibs.ac.cn
Vaccine Research Center, Key Laboratory of Molecular Virology \&

Immunology, Institut Pasteur of Shanghai, Chinese Academy of Sciences, Shanghai 200031, China
}

(C) 2016 Chi and Zhou. Open Access This article is distributed under the terms of the Creative Commons Attribution 4.0 International License (http://creativecommons.org/licenses/by/4.0/), which permits unrestricted use, distribution, and reproduction in any medium, provided you give appropriate credit to the original author(s) and the source, provide a link to the Creative Commons license, and indicate if changes were made. The Creative Commons Public Domain Dedication waiver (http://creativecommons.org/publicdomain/zero/1.0/) applies to the data made available in this article, unless otherwise stated. cesses such as cell proliferation, cell differentiation and apoptosis [7-10]. In the past 20 years, more evidence has emerged showing that miRNAs are also involved in cancer development. Aberrant expression of miRNAs is detected in various types of cancer including breast cancer, lung cancer, pancreatic cancer, colorectal carcinoma and ovarian cancer [11-14]. MiRNAs regulate expression of many known oncogenes and tumor suppressor genes in cancer pathogenesis $[15,16]$. Studying the specific function of miRNAs in human carcinogenesis will help to identify new targets for cancer research, diagnosis and treatment.

CRC is the second most common malignancy in women, and the third in men, worldwide. More than 1 million new cancer-related cases and 600,000 deaths are expected to occur each year $[17,18]$. Many risk factors associated with CRC include excessive alcohol use, obesity, older age, some genetic mutations and chronic intestinal inflammation. Generally, CRC consists of inflammatory colitis-associated cancer (CAC) and non-inflammatory adenomatous CRC. Inflammatory bowel disease (IBD) is always associated with CAC and about $20 \%$ IBD patients develop CAC 30 years after the onset of disease [19]. Like 
other types of cancer, colorectal carcinogenesis is a multistep and complex process including tumor initiation, promotion and metastasis. Recent studies have revealed that the pathogenic mechanisms of CRC depend on several signaling pathways, including the p53, PI3K, RAS, MAPK, EMT transcription factors, and $\mathrm{Wnt} / \beta$-catenin pathways. Furthermore, it has become increasingly clear that miRNAs regulate these pathways involved in the CRC pathogenesis (Table 1). For example, reduced expression of miR-143 contributes to CRC development through derepressing KRAS expression [20]. MiR-133a regulates CRC by inhibiting MAPK pathways [21].

To summarize the roles and mechanisms of miRNAs involved in CRC, it is important to be pointed out that CRC is a heterogeneous cancer including both colon cancer and rectal cancer while numerous literatures misused the term CRC in many cases [22]. From the clinical point of view, colon cancer and rectal cancer should be treated separately. Unfortunately, the majority of previous studies failed to separate these two entities. Here we distinguish the respective miRNAs in these two cancers based on the related references although very limited data about miRNAs in the rectal cancer are available [23-29].

\section{Role of miRNAs in CRC Inflammation}

Various environmental causes contribute to colorectal inflammation, including microbial infections, metabolic disorders, toxins and dietary factors [30-32]. Growing evidence indicates that a plethora of miRNAs will target inflammatory signaling molecules to induce or inhibit chronic inflammation and inflammation-related cancer (Fig. 1) [19, 33].

The nuclear transcription factor, NF- $\mathrm{kB}$ and signal transducer and activator of transcription 3 (STAT3) maintain constitutive activation of pro-inflammatory pathways as essential components in the development of CAC tumors [34-36]. Targeting negative regulators of NF- $\mathrm{KB}$ signaling through miRNAs, e.g., miR-324-5p-CUEDC2, miR-21PTEN, miR-181b-1-CYLD, miR-146-TRAF and miR-126$\mathrm{IKBa}$, result in inflammation hyperresponsiveness and tumorigenesis. MiR-324-5p, a new CRC-associated miRNA, regulates CUEDC2 levels during monocyte to macrophage differentiation [37]. Elevation of miR-324-5p levels results in decreased expression of CUEDC2 in macrophages infiltrated in mouse colon tumors and isolated from fresh colon tumor samples, which produces excess tumor-promoting cytokines and promotes pathogenic progress of CRC. The function of STAT3 in cellular transformation involves the direct activation of miR-21 and miR-181b-1 transcription by binding multiple sites in the miRNA promoter [38]. Overexpression of miR-21 or miR-181b-1 is sufficient to induce a stable transformed state by directly targeting PTEN and CYLD expression, respectively, which in turn activates NF- $\mathrm{kB}$ pathway. MiRNAs targeting NOD2, such as miR-122, miR-192, miR-495, and miR671 decrease the pro-inflammatory cytokines by regulating the activation of NF- $\mathrm{kB}$ pathway $[39,40]$. However, miR-122 is significantly increased with the stimulation of TNF- $\alpha$ and induces an increase in the intestinal epithelial tight junction permeability in vitro and in vivo [41]. Thus, the controversial role of miR-

Table 1 miRNA involvement in CRC development, diagnosis and therapy

\begin{tabular}{|c|c|c|}
\hline miRNAs & Function & References \\
\hline miR-324-5p,miR-21, miR-181b-1,miR-146, & \multirow{3}{*}{$\begin{array}{l}\text { Involved in regulation of NF-KB signaling in } \\
\text { inflammation-related CRC }\end{array}$} & \multirow[t]{3}{*}[30-50]{} \\
\hline miR-126,miR-122,miR-192,miR-495, miR-671, & & \\
\hline miR-106b,miR-30c,miR-130a & & \\
\hline miR-16,miR-218,miR-34a & Involved in the cell proliferation and survival in CRC development & [51-59] \\
\hline $\begin{array}{l}\text { miR-34a,miR-148,miR-339-5p,miR-504,miR-23a,miR-129, } \\
\text { miR-365,miR-345 }\end{array}$ & Involved in the cell death in CRC development & {$[62-74]$} \\
\hline $\begin{array}{l}\text { miR-29a,miR-29b, miR-29c,miR-200a,miR-200b,miR-200c,miR-141, } \\
\text { miR-429,miR-132,miR-192, }\end{array}$ & \multirow[t]{2}{*}{ Involved in the EMT in CRC development } & \multirow[t]{2}{*}{ [79-95] } \\
\hline miR-335,miR-34a & & \\
\hline miR-214,miR-155,miR-483,miR-133a,miR-145, & \multirow[t]{2}{*}{ Involved in the tumor invasion and metastasis in CRC development } & \multirow[t]{2}{*}{ [96-112] } \\
\hline miR-21,miR-92a,miR-17-5p,miR-221,miR-499-5p,miR-182 & & \\
\hline miR-92a-3p,miR-29a, miR-17-3p,miR-221, & \multirow[t]{3}{*}{ Involved in the clinical diagnosis of CRC } & \multirow[t]{3}{*}{ [123-129] } \\
\hline miR-19a-3p,miR-223-3p,miR-422a,miR-143, & & \\
\hline miR-145,miR-21, miR-106a,miR-92a, miR-144 & & \\
\hline miR-135b,miR-27b,miR-4689,miR-483-5p, & \multirow[t]{3}{*}{ Involved in the therapy of CRC } & \multirow[t]{3}{*}[131-152]{} \\
\hline miR-551a,miR-34a,miR-22,miR129,miR-365, & & \\
\hline miR-143,miR-21,miR-23a,miR-124 & & \\
\hline
\end{tabular}




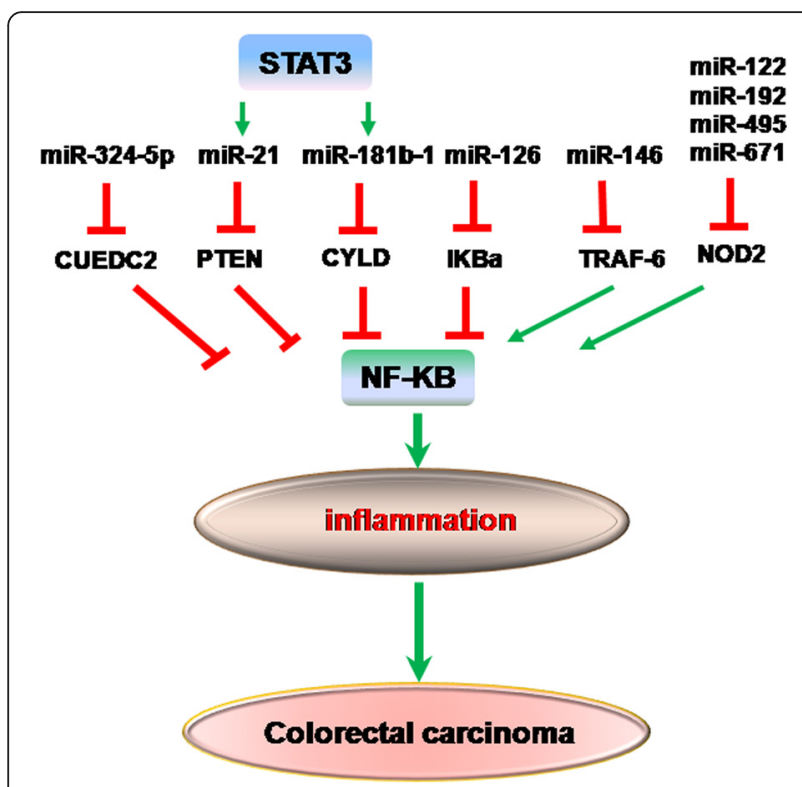

Fig. 1 MiRNAs in inflammation-related colorectal carcinoma. NF-KB signaling maintained constitutive activation of pro-inflammatory pathways as essential components during carcinogenesis. Many miRNAs target NF-kB signaling molecules to inhibit (miR-324-5p, miR-21, miR181b-1, miR-126) or promote (miR-146, miR-122, miR-192, miR-495, miR671) inflammatory response in the development of colorectal carcinoma

122 in the development of IBD should be further explored.

In accordance with previous works, miR-21 levels were often higher in inflammation and CRC than that of normal tissue [42-44]. MiR-21 is upregulated in IBD and acute intestinal obstruction (AIO) patients. In miR-21 knockout mice suffering from dextran sulfate sodium salt (DSS)-induced fatal colitis, the survival rate is improved and the ameliorative inflammatory response better protects against inflammation and tissue injury [45]. Also, miR-21 deletion exacerbates CD4+ T-cell-mediated models of acute and chronic DSS and TNBS colitis. In addition, some evidence indicates that miR-21 plays a pro-inflammatory role in IBD by impairing intestinal barrier function [46]. The increase in intestinal permeability and epithelial cells apoptosis induced by DSS are attenuated in miR-21 knockout mice.

Autophagy, involved in recycling cellular organelles for maintaining homeostasis, is considered to clear intracellular microorganisms [47]. The impairment of autophagy results in intestinal epithelial dysfunction and contributes to IBD pathogenesis [48]. Inflamed mucosae from subjects with active $C D$ have higher miR-106b and lower ATG16L1 levels indicating an altered antibacterial activity that is mediated by miR-106b which subsequently affects the outcome of intestinal inflammation [49]. MiR-106b may target ATG16L1 and reduce the level of autophagy in HCT116 cells and inhibit autophagy-dependent clearance of $\mathrm{CD}$-associated adherent-invasive Escherichia coli
(AIEC) in epithelial cells. Another study showed the expression of miR-30c and miR-130a were inversely correlated with ATG5 and ATG16L1 in intestinal epithelial cells. The inhibition of the activity of autophagy by miRNAs promotes the persistence of AIEC and the production of pro-inflammatory cytokines [50].

\section{Cell survival}

Cellular proliferation and survival have crucial roles in the process of carcinogenesis. Abnormal expression of miRNAs regulates CRC development via targeting several cell cycle regulators, including survivin and cyclins. Survivin is a direct target of miR-16 [51]. MiR16 represses CRC cell growth and induces cell apoptosis by regulating the $\mathrm{p} 53 /$ survivin signaling pathway. These observations suggest that survivin is mainly expressed during the G2/M phase of the cell cycle and therefore inhibiting survivin expression can lead to defective cytokinesis and cell cycle arrest at G2/M phase [52]. Among the other miRNAs that control cell cycle progression, miR-218 induces cell cycle arrest in the G2 phase of colon cancer cells by suppressing cyclindependent kinase4 (CDK4) and upregulating the level of p53 [53]. A recent study conducted by Cai et al. demonstrated that miR-144 inhibited cell proliferation in rectal cancer cell line SW137 and SW1463 by downregulating Rock-1. However, the aberrant expression of miR-144 is only present in the rectal cancer but not in the colon cancer [54].

The role of miR-34a to CRC development was already clarified with miR-34a inhibiting colon cancer cell proliferation by downregulating the E2F pathway and resulting in accumulation of p53 and p21 [55]. Recent studies have revealed that $\mathrm{PAR}_{2}$ promotes cancer cell proliferation through the activation of EGFR, MAPK and other survival signals and promotes the accumulation of Cyclin D1 which plays important roles in tumorigenesis $[56,57]$. Further investigations show that miR-34a mediated $\mathrm{PAR}_{2}$-induced proliferation and inhibition of miR-34a partially restores the activation of Cyclin D1 induced by $\mathrm{PAR}_{2}$ deficiency. Colon cancer stem cells (CCSCs) retain the self-renewal capacity and less limiting proliferative potential while being substantially resistant to most conventional anticancer therapies [58]. Moreover, various conserved pathways, such as Notch and Wnt, as a complex crosstalk network between CCSCs and microenvironment, are regulated in CRC. MiR-34a in the regulation of CCSCs self renewal is involved in the suppression of Notch signaling, which contributes to asymmetric cell division of stem cells [59]. Altogether, this finding reveals a unique miR-34aregulated mechanism of the toggle switch necessary for Notch bimodality that converts noisy signals into unambiguous states for robust cell-fate decisions in CCSCs. 


\section{Cell death}

The p53 protein is a transcription factor that is activated in response to cellular stresses to inhibit cell proliferation and stimulate cell death [60]. Disruption of the p53 pathway can promote tumorigenesis [61]. MiR-34a mediated inhibition of SIRT1 expression leads to apoptosis due to the increase of acetylated p53 formed a positive feedback loop of miR-34a and p53 [62]. Moreover, transient introduction of miR-34a into SW480 cells contributes to a severe decrease in migration and invasion by upregulating acetylated p53 and p21 [63]. It also suggests that an overexpression of miR-34a induces cell growth arrest and senescence-like phenotypes through upregulating the p53 pathway [55]. The increase of p55PIK in CRC can accelerate cell cycle progression by interacting with retinoblastoma protein or proliferation cell nuclear antigen $[64,65]$. The introduced miR-148b, by suppressing p55PIK abolishes cell proliferation and cell cycle progression in CRC [66]. Furthermore, p53 directly activates the transcription of miR-148 which negatively regulates p55PIK expression. A reduction of miR-339-5p expression has been reported in colorectal cancer and is associated with poor prognosis in cancer patients $[67,68]$. MDM2, a key negative regulator of p53 is repressed by miR-339-5p [69]. After downregulation of MDM2 by miR-339-5p, the growth of colorectal xenograft tumors is inhibited in a p53dependent manner. The function of miR-504, that is inhibiting p53 expression, reduces cell cycle arrest and promotes tumorigenicity in vivo [70].

Apoptosis is also controlled by various networks of miRNAs. Several researches have described that proapoptotic protein can be suppressed by the overexpression of miRNAs. For example, the human homolog of the Caenorhabditis elegans cell death protein CED-4,
APAF- 1 , is controlled by miR-23a to repress the activity of caspases-3,-7 and-9 [71]. The increased miR-23a antisense can induce the apoptosis of HCT116 and HT29 cell lines, under the 5-FU treatment. It is also found that miR-23a is up-regulated in 5-FU-treated HC.21 and C22.20 cells [72]. Conversely, miR-129 can trigger apoptosis by suppressing Bcl2, an anti-apoptotic protein [73]. The Intrinsic apoptotic pathway is activated by cleavage of caspae- 9 and-3. Besides, the transfection of miR-129 in RKO cells and HCT116 cells causes cell cycle arrest in G1 or G2 phase. In human CRC tissues, miR-129 is significantly decreased in patients with stage 3 and stage 4 tumors. The other miRNAs, such as miR-365 and miR-345, also affect the antitumor capability, respectively by targeting the antiapoptosis protein of $\mathrm{Bcl} 2$ and $\mathrm{Bcl} 2$-associated athanogene 3 (BAG3) [74].

\section{MiRNAs and EMT}

Epithelial-to-mesenchymal transition (EMT) is involved in multiple biological processes including gastrulation, neural tube formation, tissue regeneration, and organ fibrosis [75]. EMT is an important factor in tumor metastasis undergoing a number of biochemical changes, including the decrease in epithelial cell-surface markers and cytoskeleton components, and the increase in mesenchymal markers and specific transcription factors [76-78]. Given miRNAs-regulated EMT via targeting Ecadherin and other molecules, it is likely that miRNAs play a crucial role in colorectal carcinogenesis (Fig. 2). The highly conserved pathway of Wnt/ $\beta$-catenin signaling is constitutively activated in CRC. Wnt signaling is regulated by abnormal $\beta$-catenin activation associated with E-cadherin expression [79]. Also, miR-101, miR-

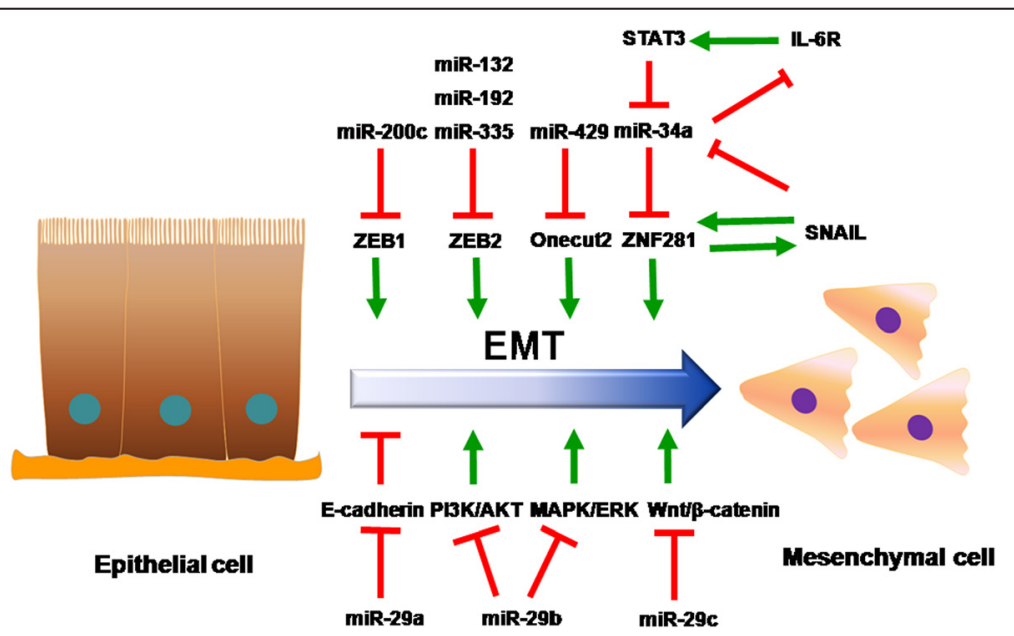

Fig. 2 Regulation of epithelial mesenchymal transition (EMT) in colorectal carcinogenesis by miRNAs. Many miRNAs, such as miR-29b, miR-29c, miR-200c, miR-34a, regulate EMT by suppressing EMT-related transcription factors and signaling pathways. The other miRNAs, such as miR-29a, promote EMT in colorectal carcinogenesis 
224 and miR-574-5p can affect CRC malignant features by regulating Wnt/ $\beta$-catenin signaling [80-82].

Recent studies have demonstrated that the members of the miR-29 family (miR-29a, miR-29b and miR-29c) are involved in the tumor progression by regulating EMT. MiR-29c is dramatically downregulated in CRC tissues and suppresses EMT in vitro, hence it has a role in cell migration and invasion by negatively regulating the Wnt/ $\beta$-catenin signaling pathway [83]. Similarly, miR-29b suppresses EMT and plays an important role in cell migration and invasion by negatively regulating the MAPK/ERK and PI3K/AKT pathways [84]. However, overexpression of miR-29a promotes cell invasion by inhibiting E-cadherin expression [85].

The importance of the miR-200 family (miR-200a, miR-200b, miR-200c, miR-141 and miR-429) for EMT is not limited to colon carcinogenesis, because it has been widely demonstrated in various tumors [86, 87]. Indeed, restoration of miR-200c inhibits migration and invasion in various CRC cell lines via directly targeting ZEB1, the transcriptional repressor of E-cadherin [88, 89]. There is another evidence that miR-429 reverses TGF- $\beta$-induced EMT by interfering with Onecut2 in SW620 and SW480 cells [90]. In addition, ZEB2 as a direct target of miR132, miR-192 and miR-335 has been shown to regulate metastasis [91-93]. A significant decrease of these three miRNAs is associated with distant metastasis and advanced stage tumors. A few researches have indicated that miR-34a inhibits metastasis formation in CRC via EMT-regulating network in SNAIL/ZNF81 and IL6R/ STAT3 [94, 95]. These studies implicate the components of miRNA-regulating networks in EMT with traits associated with metastasis formation in CRC.

\section{Invasion and metastasis}

Over $70 \%$ of CRC patients harboring liver metastasis die due to the lack of effective therapeutics. Some miRNAs have been identified to suppress liver metastatic colonization in CRC patients. Nude mice in which ectopic miR-214 is expressed in CRC cells has a reduced amount of liver metastases, supporting the importance of intracellular dynamic regulation [96]. However, another crucial factor for metastasis is based on extracellular metabolic energetic [97]. Creatine kinase Brain (CKB) in liver metastatic cancer cells is released to the extracellular microenvironment converting ATP and creatine into phosphocreatine, which is imported into cancer cells to counteract hypoxic response. Both miR-155 and miR-483 targeting $\mathrm{CKB}$, as endogenous suppressors of colon cancer metastasis decrease significantly the ATP levels, further to impair intracellular energetic requirements to establish a barrier to metastatic progression.

MiR-133a targets LASP1 and suppresses tumor growth and metastasis by inhibiting phosphorylation of the
ERK/MEK signaling pathway [21]. Downregulation of miR-145 is detected in primary CRC tumors compared to normal tissues. MiR-145 inhibits proliferation, migration and invasion of SW620 and LoVo metastatic cell lines by targeting fascin- 1 and results in a decrease in lung metastases in nude mice [98]. Conversely, another study reveals that increased miR-145 could improve migration and invasion of HCT-8 cells and is associated with lymph node metastasis of CRC while having no effect on proliferation [99]. In addition, miR-106b promotes colorectal cancer cell migration and invasion by directly targeting DLC1 [100].

PTEN, a tumor suppressor gene, is often lost in human cancers and a common target of miR-21, miR-92a and miR-17-5p in CRC [101-104]. The levels of miR-21 and miR-92a significantly correlate with lymph node metastasis and advanced TNM stage promoting cell migration via mediating the PTEN-dependent PI3K/AKT signaling pathway. Overexpression of miR-17-5p is responsible for chemo-resistance in a cohort study of 295 patients. In addition, miR-221, miR-145, miR-499-5p and miR-182 as novel candidate prometastatic miRNAs are significantly increased in lymph node-positive CRC patients by regulating suppressor genes (cyclin dependent kinase inhibitor, RECK, FOXO4 and PDCD4) [105-109].

The small GTPases Cdc42 is essential for intestinal stem cell division, survival and differentiation to maintain the homeostasis [110]. In addition, Cdc42 is required higher expression in human CRCs relating to poorly differentiated CRCs [111]. In the APC-mutant or $\beta$-catenin-mutant mice, Cdc42 reduction attenuates the tumorigenesis of mutant intestinal cells [112]. In the same way, human colorectal cancer with higher levels of Cdc42 activity was especially sensitive to Cdc42 blockade. Expression of miR224 in CRC tissue specimens is significantly lower than in nontumor tissues and paired adjacent samples [113]. Ectopic expression of miR-224 inhibits the migratory ability of HCT116 cells, but the cell growth rate is less affected. Increased miR-224 suppresses CRC cell migration by diminishing Cdc42 and SMAD4 expressions and inhibiting the formation of actin filaments.

\section{MiRNAs as clinical diagnosis}

Given the invasive nature and expensive cost of current screening methods of CRC diagnosis including FOBT, CEA and colonoscopy, it is difficult to detect CRC early and efficiently [114-116]. As well as the importance of miRNAs in the CRC development, miRNAs could serve as potential biomarkers in CRC diagnosis based on the high degree of stability, specificity and sensitivity of miRNAs in the blood and stool [117-122].

Since the first study in 2008 reported cancer-specific miRNAs secreted in the blood among the different cancer types, a spectrum of miRNAs associated with CRC in the 
blood have been identified including miR-92a, miR-29a, miR-17-3p, miR-221, miR-19a-3p, miR-223-3p and miR422a et al. [123-126]. Although ribonuclease exists in serum, circulating extracellular miRNAs are found in the blood of healthy and cancer-related patients. Chen et al. systematically identified specific patterns of serum miRNAs expression in several diseases including lung cancer, CRC, and diabetes [123]. This study showed that $69 \mathrm{miR}-$ NAs were detected in the blood of CRC patients but not in the normal serum. Unsuprisingly, many circulating miRNAs such as miR-221 are also present in the blood of lung cancer. $\mathrm{Ng}$ et al. discovered that both miR-92a and miR-17-3p were significantly upregulated in the plasma of CRC patients compared to normal plasma [125]. Zheng et al. recently identified four miRNAs panels (miR-19a-3p, miR-223-3p, miR-92a-3p and miR-422a) with a high diagnostic accuracy of CRC [124].

MiRNAs disturbance in the stool of CRC patients can also offer a possibility for a stool-base miRNA test as a common used method for CRC diagnosis. A number of studies support this potential diagnostic method of CRC by finding that many miRNAs are downregulated (miR-143, miR-145) or overexpressed (miR-21, miR-106a, miR-92a, miR-144) in the fecal samples of CRC patients compared to healthy subjects [127-130]. It is of interest to note that Wang et al. found that the expression level of miR-92a in the stool of CRC patients was significantly higher than control, which was very similar to the dysregulated expression of miR-92a in the blood [129]. Thus, miRNAs can be represented highly effective and accurate biomarkers for the future CRC diagnosis.

\section{MiRNA-based therapies}

Potential application of targeting miRNAs is increasing in gene therapy testing and preclinical studies. The development of mouse models generates key biological and molecular events based on human conditions. The efficacy of miRNA-mediated CRC therapy is following current technologies through various strategies.

Traditional preclinical mouse models of CRC induced by colitis - associated cancer (CAC) have been established with two drugs of azoxymethane (AOM) and DSS as the results of mutations containing PI3K, K-ras and catenin pathways. Another CDX2P-NLS Cre;Apc+/loxP (CPC; Apc) mouse model harbors a truncating mutation affecting one APC allele [131]. Compared to normal tissues, 57 miRNAs are aberrantly expressed in tumors in the AOM/DSS model while 35 miRNAs are aberrantly expressed in polyps from CPC; Apc mice [132]. Among the overexpressed miRNAs, miR$135 \mathrm{~b}$ is consistently the highest expressed one in both models. High miR-135b expression is correlated with tumor stage and poor overall survival by analyzing 454 sporadic and 31 IBD-associated CRCs. The use of locked nucleic acid (LNA) anti-miR-135b induces apoptosis of SW480 cells while oligonucleotides specific silencing miR-135b effectively inhibited tumor proliferation in both mouse models. A study by Wu et al. indicated miR-135b mimicstransfected HCT-116 cells exhibited significantly increased migratory ability, while inverse effects were detected with the treatment of inhibitors [133]. Thus, miR-135b may be a promising therapeutic target in CRC treatment with improving specificity and limiting toxicity [134]. In addition to miR-135b, other oncogeic miRNAs are also potential candidates for CRC therapy. For example, successful knockdown of miR-21 by using LNA in SW480 cells and antisense oligonucleotide-based inhibition of miR-20a, miR-21,miR31, miR-95, miR-675 in SW480, SW620, and HCT116 cells showed potential value for future translational treatment [135-139]. Although LNA and antisense oligonucleotide are efficient in blocking oncogenic miRNA, some novel approaches like miRNA sponge, miRNA masking and small molecule inhibitors are emerging. Jung and colleagues recently reported the use of miRNA sponges in human breast cancer cell lines [140]. They demonstrated a multi-potent miRNA sponge that simultaneously inhibits four oncogenic miRNAs including miR-21, miR-155,miR-221, miR-222. The multi-potent miRNA sponge inhibit cancer cell migration partially through the upregulation of Foxo3a,PTEN. Moreover they found that the antitumor function of the multi-potent miRNA sponge is much stronger than single miRNA targeting sponge and the four miRNAs used in this study had oncogenic functions in CRC. Future utility of the multi-potent miRNA sponge in the CRC treatment will be a promising and effective strategy. Being different from miRNA sponge,miRNA masking technology is developed by Choi et al. [141]. It consists of single-stranded 2'-O-methyl-modified antisense oligonucleotides that can fully bind to the 3'UTR of the target mRNA. One of the advantage of this technology is off-target effect can be significantly reduced which attracts the researchers' attention in the CRC treatment. The screen of small molecule inhibitors of miRNA is being rapidly developed. Tripp et al. discovered small molecule inhibitors of miR-122 could be applied in the HCV therapy [142]. This novel approach combining other conventional CRC cancer therapeutics will play important roles in the future.

Another strategy to provide preclinical tools is miRNA restoration. Several miRNAs acting as tumor suppressors are generally downregulated in tumors. It has been demonstrated that the inhibition of tumor growth and angiogenesis is detected in xenografts of miR-27b mimics [143]. The utility of miRNAs mimics will provide a great clinical value for targeted therapies that identifies the cancerrelated regulators. $\mathrm{PH}$ sensitive systemic administration of carbonate apatite nanoparticle-formulated miR-4689 reveals dramatically the inhibition of tumor growth in mouse xenografts with decreasing MAPK/ERK and PI3K/ AKT signaling pathways [144]. In vitro colon cancer cells 
and in vivo mice bearing hepatic metastases models have been employed to test the tumor suppressor activity of miR-483-5p and miR-551a delivered by adeno-associated viruses (AAV) [97]. MiR-34a-/- mice have displayed an increased incidence and size of tumor with AOM/DSS challenge [95]. The expression of miR-34a is inhibited by specific antagomirs, a single strand RNA complementary to the targeted miRNA, which enhances the invasion of CRC cancer cells. However, ectopic expression of miR-34a can prevent IL-6-indiced EMT and invasion in DLD-1 cells. Likewise, miR-143 was found to be dramatically downregulated in the human CRC tissues as a tumor suppressor miRNA. Ng et al. increased miR-143 expression by transfection with miR-143 precursor in colon cancer cells [145], and found that restoration of miR-143 not only inhibited tumor cell growth but also affected malignant transformation phenotypes. Nakagawa et al. reported the increased expression level of miR-143 by $\alpha$-mangostin induced human colon cancer DLD-1 cell death [146]. Taken together, restoring miRNA-based delivery systems as viable paths clinically is able to control cancer progression in cell tests and mouse models without any adverse outcomes.

A major obstacle to successful treatment for cancer is resistance to chemotherapy and radiation. Recently, miRNAs are being investigated as a predictor or a therapeutic target to improve the efficacy of 5-FU chemotherapy in CRC treatment. Various studies have shown that treatment with miR-22, miR-129, miR-365 and miR-143 increase sensitivity to 5 -FU treatment in vitro and in vivo $[73,74,147,148]$. However, high expression of miR-21 significantly decreases G2/M arrest and apoptosis after 5-FU treatment [137]. Silencing miR-21 inhibits cell proliferation and restores sensitivity of chemotherapy in HT-29 cells [149]. Moreover, miR-23a increases the chemoresistance to 5-FU in CRC cells though targeting ABCF1 [150]. A miRNA array screening revealed that miR-203 was significantly accumulated in oxanliplatin-resistant CRC cell lines [151]. Oxaliplatin is known to induce cell cycle arrest and cell apoptosis with a combination of therapeutic regimen for patients with metastatic CRC. In addition, the greater sensitivity to radiation is found in the treatment of miR-124 mimics to CRC cells and in the miR-124-overexpressed cells among in vivo mouse xenografts [152]. Therefore, understanding the miRNA-regulating mechanisms of resistance to chemotherapeutic agents would ultimately help us in improving therapeutic outcomes and identifying new targets and drugs.

\section{Conclusions}

CRC is one of the most common malignancies in human. For patients with advanced CRC, the optimal treatment strategies currently depend on tumor staging and metastasis to reduce the risk of recurrence [153]. Resectable CRC is supported by combination with chemotherapy and nonresectable CRC, the systemic therapy options involve in palliative chemotherapy and monoclonal antibodies. However, more effective treatments with less cumulative toxicity and drug resistance are urgently needed.

The roles of miRNAs in tumor growth and the regulation of tumor progress summarized here suggest miRNAs could be a potential means for diagnosis and treatment of CRC as well as prognostic parameters for CRC. Future investigations will highlight the diseasespecific or cell-specific expression patterns of miRNAs in CRC, which will be helpful to identify novel potential targets and improve our understanding of miRNA regulatory mechanisms. Moreover, extracellular miRNAs associated with cancer cells has recently emerged as new topic to explore and will expand the knowledge of tumor microenvironment modulation in CRC.

\section{Competing interest}

The author declares that they have no competing interests.

\section{Authors' contributions}

DZ and YC conceived the study. YC searched the literature and drafted the manuscript. DZ edited and approved the final manuscript. Both authors read and approved the final manuscript.

\section{Acknowledgements}

This work was supported by grants from "Knowledge Innovation Program" (No.Y014P31503) and "100 Talent Program" (No.Y316P11503) of Chinese Academy of Sciences and Shanghai Pasteur Foundation.

Received: 16 November 2015 Accepted: 7 March 2016

Published online: 10 March 2016

\section{References}

1. Lee RC, Feinbaum RL, Ambros V. The C. elegans heterochronic gene lin-4 encodes small RNAs with antisense complementarity to lin-14. Cell. 1993:75:843-54.

2. Lau NC, Lim LP, Weinstein EG, Bartel DP. An abundant class of tiny RNAs with probable regulatory roles in Caenorhabditis elegans. Science (New York, NY). 2001;294:858-62.

3. Ambros $V$. The functions of animal microRNAs. Nature. 2004:431:350-5.

4. Bartel DP. MicroRNAs: genomics, biogenesis, mechanism, and function. Cell. 2004;116:281-97.

5. He L, Hannon GJ. MicroRNAs: small RNAs with a big role in gene regulation. Nat Rev Genet. 2004:5:522-31.

6. Bartel DP. MicroRNAs: target recognition and regulatory functions. Cell. 2009;136:215-33.

7. Cheng LC, Tavazoie M, Doetsch F. Stem cells: from epigenetics to microRNAs. Neuron. 2005;46:363-7.

8. Reinhart BJ, Slack FJ, Basson M, Pasquinelli AE, Bettinger JC, Rougvie AE, Horvitz HR, Ruvkun G. The 21-nucleotide let-7 RNA regulates developmental timing in Caenorhabditis elegans. Nature. 2000:403:901-6.

9. Suh MR, Lee Y, Kim JY, Kim SK, Moon SH, Lee JY, Cha KY, Chung HM, Yoon HS, Moon SY, Kim VN, Kim KS. Human embryonic stem cells express a unique set of microRNAs. Dev Biol. 2004;270:488-98.

10. Cimmino A, Calin GA, Fabbri M, lorio MV, Ferracin M, Shimizu M, Wojcik SE, Aqeilan RI, Zupo S, Dono M, Rassenti L, Alder H, Volinia S, Liu CG, Kipps TJ, Negrini M, Croce CM. miR-15 and miR-16 induce apoptosis by targeting BCL2. Proc Natl Acad Sci USA. 2005;102:13944-9.

11. Iorio MV, Ferracin M, Liu CG, Veronese A, Spizzo R, Sabbioni S, Magri E, Pedriali M, Fabbri M, Campiglio M, Menard S, Palazzo JP, Rosenberg A, Musiani P, Volinia S, Nenci I, Calin GA, Querzoli P, Negrini M, Croce CM. MicroRNA gene expression deregulation in human breast cancer. Cancer Res. 2005;65:7065-70. 
12. Hayashita $Y$, Osada H, Tatematsu Y, Yamada H, Yanagisawa $K$, Tomida S, Yatabe $Y$, Kawahara K, Sekido Y, Takahashi T. A polycistronic microRNA cluster, miR-17-92, is overexpressed in human lung cancers and enhances cell proliferation. Cancer Res. 2005;65:9628-32.

13. Michael MZ, SM OC, van Holst Pellekaan NG, Young GP, James RJ. Reduced accumulation of specific microRNAs in colorectal neoplasia. Mol Cancer Res. 2003;1:882-91

14. Zhang B, Pan X, Cobb GP, Anderson TA. microRNAs as oncogenes and tumor suppressors. Dev Biol. 2007;302:1-12.

15. Lee YS, Dutta A. MicroRNAs: small but potent oncogenes or tumor suppressors. Curr Opin Investig Drugs. 2006;7:560-4.

16. Shenouda SK, Alahari SK. MicroRNA function in cancer: oncogene or a tumor suppressor? Cancer Metastasis Rev. 2009;28:369-78.

17. Jemal A, Bray F, Center MM, Ferlay J, Ward E, Forman D. Global cancer statistics. CA Cancer J Clin. 2011;61:69-90.

18. Ferlay J, Shin HR, Bray F, Forman D, Mathers C, Parkin DM. Estimates of worldwide burden of cancer in 2008: GLOBOCAN 2008. Int J Cancer. 2010; 127:2893-917.

19. Grivennikov SI. Inflammation and colorectal cancer: colitis-associated neoplasia. Semin Immunopathol. 2013;35:229-44.

20. Chen X, Guo X, Zhang H, Xiang Y, Chen J, Yin Y, Cai X, Wang K, Wang G, Ba Y, Zhu L, Wang J, Yang R, Zhang Y, Ren Z, Zen K, Zhang J, Zhang CY. Role of miR143 targeting KRAS in colorectal tumorigenesis. Oncogene. 2009;28:1385-92.

21. Wang H, An H, Wang B, Liao Q, Li W, Jin X, Cui S, Zhang Y, Ding Y, Zhao L. miR-133a represses tumour growth and metastasis in colorectal cancer by targeting LIM and SH3 protein 1 and inhibiting the MAPK pathway. Eur J Cancer. 2013;49:3924-35.

22. Li X, Zhang G, Luo F, Ruan J, Huang D, Feng D, Xiao D, Zeng Z, Chen X, Wu W. Identification of aberrantly expressed miRNAs in rectal cancer. Oncol Rep. 2012;28:77-84.

23. Gaedcke J, Grade M, Camps J, Sokilde R, Kaczkowski B, Schetter AJ, Difilippantonio MJ, Harris CC, Ghadimi BM, Moller S, Beissbarth T, Ried T, Litman T. The rectal cancer microRNAome-microRNA expression in rectal cancer and matched normal mucosa. Clin Cancer Res. 2012;18: 4919-30.

24. Slattery ML, Wolff E, Hoffman MD, Pellatt DF, Milash B, Wolff RK. MicroRNAs and colon and rectal cancer: differential expression by tumor location and subtype. Genes Chromosomes Cancer. 2011;50:196-206.

25. Svoboda M, Izakovicova Holla L, Sefr R, Vrtkova I, Kocakova I, Tichy B, Dvorak J. Micro-RNAs miR125b and miR137 are frequently upregulated in response to capecitabine chemoradiotherapy of rectal cancer. Int J Oncol. 2008:33:541-7.

26. Svoboda M, Sana J, Fabian P, Kocakova I, Gombosova J, Nekvindova J, Radova L, Vyzula R, Slaby O. MicroRNA expression profile associated with response to neoadjuvant chemoradiotherapy in locally advanced rectal cancer patients. Radiat Oncol. 2012;7:195.

27. Dai J, Wu W, Zhou J, Gao K, Hu G, Lin C, Zhang Y, Li X. Effect of antisense microRNA targeting survivin on rectal cancer HRC-9698 cells and its mechanism. Int J Clin Exp Pathol. 2015:8:6057-63.

28. Yang $Y$, Peng W, Tang T, Xia L, Wang XD, Duan BF, Shu Y. MicroRNAs as promising biomarkers for tumor-staging: evaluation of MiR21 MiR155 MiR29a and MiR92a in predicting tumor stage of rectal cancer. Asian Pac J Cancer Prev. 2014;15:5175-80.

29. Yang Y, Tang T, Peng W, Xia L, Wang X, Duan B, Shu Y. The comparison of miR155 with computed tomography and computed tomography plus serum amyloid A protein in staging rectal cancer. J Surg Res. 2015;193:764-71.

30. Sears CL, Garrett WS. Microbes, microbiota, and colon cancer. Cell Host Microbe. 2014;15:317-28

31. Shivappa N, Prizment AE, Blair CK, Jacobs Jr DR, Steck SE, Hebert JR. Dietary inflammatory index and risk of colorectal cancer in the lowa Women's Health Study. Cancer Epidemiol Biomark Prev. 2014;23:2383-92.

32. Zamora-Ros R, Shivappa N, Steck SE, Canzian F, Landi S, Alonso MH, Hebert JR, Moreno V. Dietary inflammatory index and inflammatory gene interactions in relation to colorectal cancer risk in the Bellvitge colorectal cancer case-control study. Genes Nutr. 2015;10:447.

33. Terzic J, Grivennikov S, Karin E, Karin M. Inflammation and colon cancer. Gastroenterology. 2010;138:2101-2114.e2105.

34. Ullman TA, Itzkowitz SH. Intestinal inflammation and cancer. Gastroenterology. 2011;140:1807-16.

35. Yu H, Pardoll D, Jove R. STATs in cancer inflammation and immunity: a leading role for STAT3. Nat Rev Cancer. 2009;9:798-809.
36. Lee H, Herrmann A, Deng JH, Kujawski M, Niu G, Li Z, Forman S, Jove R, Pardoll DM, Yu H. Persistently activated Stat3 maintains constitutive NFkappaB activity in tumors. Cancer Cell. 2009;15:283-93.

37. Chen Y, Wang SX, Mu R, Luo X, Liu ZS, Liang B, Zhuo HL, Hao XP, Wang Q, Fang DF, Bai ZF, Wang QY, Wang HM, Jin BF, Gong WL, Zhou T, Zhang XM, Xia Q, Li T. Dysregulation of the miR-324-5p-CUEDC2 axis leads to macrophage dysfunction and is associated with colon cancer. Cell reports. 2014;7:1982-93.

38. Iliopoulos D, Jaeger SA, Hirsch HA, Bulyk ML, Struhl K. STAT3 activation of miR-21 and miR-181b-1 via PTEN and CYLD are part of the epigenetic switch linking inflammation to cancer. Mol Cell. 2010;39:493-506.

39. Chuang AY, Chuang JC, Zhai Z, Wu F, Kwon JH. NOD2 expression is regulated by microRNAs in colonic epithelial HCT116 cells. Inflamm Bowel Dis. 2014;20:126-35.

40. Chen $Y$, Wang $C$, Liu Y, Tang L, Zheng M, Xu C, Song J, Meng X. miR-122 targets NOD2 to decrease intestinal epithelial cell injury in Crohn's disease. Biochem Biophys Res Commun. 2013;438:133-9.

41. Ye D, Guo S, Al-Sadi R, Ma TY. MicroRNA regulation of intestinal epithelial tight junction permeability. Gastroenterology. 2011;141:1323-33.

42. Chapman CG, Pekow J. The emerging role of miRNAs in inflammatory bowel disease: a review. Ther Adv Gastroenterol. 2015:8:4-22.

43. Schetter AJ, Nguyen GH, Bowman ED, Mathe EA, Yuen ST, Hawkes JE, Croce CM, Leung SY, Harris CC. Association of inflammation-related and microRNA gene expression with cancer-specific mortality of colon adenocarcinoma. Clin Cancer Res. 2009;15:5878-87.

44. Schetter AJ, Leung SY, Sohn JJ, Zanetti KA, Bowman ED, Yanaihara N, Yuen ST, Chan TL, Kwong DL, Au GK, Liu CG, Calin GA, Croce CM, Harris CC. MicroRNA expression profiles associated with prognosis and therapeutic outcome in colon adenocarcinoma. Jama. 2008;299:425-36.

45. Shi C, Liang Y, Yang J, Xia Y, Chen H, Han H, et al. MicroRNA-21 knockout improve the survival rate in DSS induced fatal colitis through protecting against inflammation and tissue injury. PLoS One. 2013;8:e66814.

46. Yang $Y$, Ma Y, Shi C, Chen H, Zhang H, Chen N, et al. Overexpression of miR-21 in patients with ulcerative colitis impairs intestinal epithelial barrier function through targeting the Rho GTPase RhoB. Biochem Biophys Res Commun. 2013:434:746-52.

47. Mizushima N, Komatsu M. Autophagy: renovation of cells and tissues. Cell. 2011;147:728-41.

48. Patel KK, Stappenbeck TS. Autophagy and intestinal homeostasis. Annu Rev Physiol. 2013;75:241-62.

49. Zhai Z, Wu F, Chuang AY, Kwon JH. miR-106b fine tunes ATG16L1 expression and autophagic activity in intestinal epithelial HCT116 cells. Inflamm Bowel Dis. 2013;19:2295-301.

50. Nguyen HT, Dalmasso G, Muller S, Carriere J, Seibold F, Darfeuille-Michaud A. Crohn's disease-associated adherent invasive Escherichia coli modulate levels of microRNAs in intestinal epithelial cells to reduce autophagy. Gastroenterology. 2014;146:508-19.

51. Ma Q, Wang X, Li Z, Li B, Ma F, Peng L, et al. microRNA-16 represses colorectal cancer cell growth in vitro by regulating the p53/survivin signaling pathway. Oncol Rep. 2013;29:1652-8.

52. Li F, Ackermann EJ, Bennett CF, Rothermel AL, Plescia J, Tognin S, et al. Pleiotropic cell-division defects and apoptosis induced by interference with survivin function. Nat Cell Biol. 1999;1:461-6.

53. He X, Dong Y, Wu CW, Zhao Z, Ng SS, Chan FK, et al. MicroRNA-218 inhibits cell cycle progression and promotes apoptosis in colon cancer by downregulating BMI1 polycomb ring finger oncogene. Mol Med. 2012;18:1491-8.

54. Cai SD, Chen JS, Xi ZW, Zhang LJ, Niu ML, Gao ZY. MicroRNA144 inhibits migration and proliferation in rectal cancer by downregulating ROCK1. Mol Med Rep. 2015;12:7396-402.

55. Tazawa H, Tsuchiya N, Izumiya M, Nakagama H. Tumor-suppressive miR34 a induces senescence-like growth arrest through modulation of the E2F pathway in human colon cancer cells. Proc Natl Acad Sci USA. 2007; 104:15472-7.

56. Ohta T, Shimizu K, Yi S, Takamura H, Amaya K, Kitagawa H, et al. Proteaseactivated receptor-2 expression and the role of trypsin in cell proliferation in human pancreatic cancers. Int J Oncol. 2003;23:61-6.

57. Ma Y, Bao-Han W, Lv X, Su Y, Zhao X, Yin Y, et al. MicroRNA-34a mediates the autocrine signaling of PAR2-activating proteinase and its role in colonic cancer cell proliferation. PLoS One. 2013;8:e72383.

58. Frank NY, Schatton T. Frank MH. The therapeutic promise of the cancer stem cell concept. J Clin Invest. 2010;120:41-50. 
59. Bu P, Chen KY, Chen JH, Wang L, Walters J, Shin YJ, et al. A microRNA miR34a-regulated bimodal switch targets Notch in colon cancer stem cells. Cell Stem Cell. 2013;12:602-15.

60. Kastan MB, Zhan Q, El-Deiry WS, Carrier F, Carrier F, Jacks T, et al. A mammalian cell cycle checkpoint pathway utilizing p53 and GADD45 is defective in ataxia-telangiectasia. Cell. 1992;71:587-97.

61. Vousden $\mathrm{KH}$, Prives C. Blinded by the Light: The Growing Complexity of p53. Cell. 2009;137:413-31.

62. Yamakuchi M, Ferlito M, Lowenstein CJ. miR-34a repression of SIRT1 regulates apoptosis. Proc Natl Acad Sci U S A. 2008;105:13421-6.

63. Lai M, Du G, Shi R, Yao J, Yang G, Wei Y, et al. MiR-34a inhibits migration and invasion by regulating the SIRT1/p53 pathway in human SW480 cells. Mol Med Rep. 2015;11:3301-7.

64. Hu J, Liu S, Wang J, Luo X, Gao X, Xia X, et al. Overexpression of the Nterminal end of the p55gamma regulatory subunit of phosphatidylinositol 3-kinase blocks cell cycle progression in gastric carcinoma cells. Int J Oncol. 2005:26:1321-7.

65. Xia X, Cheng A, Akinmade D, Hamburger AW. The N-terminal 24 amino acids of the p55 gamma regulatory subunit of phosphoinositide 3-kinase binds $\mathrm{Rb}$ and induces cell cycle arrest. Mol Cell Biol. 2003;23:1717-25.

66. Wang G, Cao X, Lai S, Luo X, Feng Y, Wu J, et al. Altered p53 regulation of miR-148b and p55PIK contributes to tumor progression in colorectal cancer. Oncogene. 2015;34:912-21.

67. Zhou C, Liu G, Wang L, Lu Y, Yuan L, Zheng L, et al. MiR-339-5p regulates the growth, colony formation and metastasis of colorectal cancer cells by targeting PRL-1. PLoS One. 2013;8:e63142.

68. Li Y, Zhao W, Bao P, Li C, Ma XQ, Li Y, et al. miR-339-5p inhibits cell migration and invasion and may be associated with the tumor-nodemetastasis staging and lymph node metastasis of non-small cell lung cancer. Oncol lett. 2014;8:719-25.

69. Zhang C, Liu J, Wang X, Wu R, Lin M, Laddha SV, et al. MicroRNA-339-5p inhibits colorectal tumorigenesis through regulation of the MDM2/p53 signaling. Oncotarget. 2014;5:9106-17.

70. Hu W, Chan CS, Wu R, Zhang C, Sun Y, Song JS, et al. Negative regulation of tumor suppressor p53 by microRNA miR-504. Mol Cell. 2010;38:689-99.

71. Shang J, Yang F, Wang Y, Wang Y, Xue G, Mei Q, et al. MicroRNA-23a antisense enhances 5 -fluorouracil chemosensitivity through APAF-1/ caspase-9 apoptotic pathway in colorectal cancer cells. J Cell Biochem. 2014;115:772-84.

72. Rossi L, Bonmassar E, Faraoni I. Modification of miR gene expression pattern in human colon cancer cells following exposure to 5-fluorouracil in vitro. Pharmacol Res. 2007;56:248-53.

73. Karaayvaz M, Zhai H, Ju J. miR-129 promotes apoptosis and enhances chemosensitivity to 5-fluorouracil in colorectal cancer. Cell Death Dis. 2013;4:e659.

74. Nie J, Liu L, Zheng W, Chen L, Wu X, Xu Y, et al. microRNA-365, downregulated in colon cancer, inhibits cell cycle progression and promotes apoptosis of colon cancer cells by probably targeting Cyclin D1 and Bcl-2. Carcinogenesis. 2012;33:220-5.

75. Sipos F, Galamb O. Epithelial-to-mesenchymal and mesenchymal-toepithelial transitions in the colon. World J Gastroenterol. 2012;18:601-8.

76. Kalluri R, Weinberg RA. The basics of epithelial-mesenchymal transition. J Clin Invest. 2009;119:1420-8.

77. Thiery JP, Sleeman JP. Complex networks orchestrate epithelialmesenchymal transitions. Nat Rev Mol Cell Biol. 2006;7:131-42.

78. D'Eliseo D, Di Rocco G, Loria R, Soddu S, Santoni A, Velotti F. Epitelial-tomesenchimal transition and invasion are upmodulated by tumor-expressed granzyme B and inhibited by docosahexaenoic acid in human colorectal cancer cells. J Exp Clin Cancer Res. 2016;35:24

79. Brabletz T, Jung A, Reu S, Porzner M, Hlubek F, Kunz-Schughart LA, et al. Variable beta-catenin expression in colorectal cancers indicates tumor progression driven by the tumor environment. Proc Natl Acad Sci U S A. 2001;98:10356-61

80. Strillacci A, Valerii MC, Sansone P, Caggiano C, Sgromo A, Vittori L, et al. Loss of miR-101 expression promotes Wnt/beta-catenin signalling pathway activation and malignancy in colon cancer cells. J Pathol. 2013;229:379-89.

81. Ji S, Ye G, Zhang J, Wang L, Wang T, Wang Z, et al. miR-574-5p negatively regulates Qki6/7 to impact beta-catenin/Wnt signalling and the development of colorectal cancer. Gut. 2013;62:716-26.

82. Li T, Lai Q, Wang S, Cai J, Xiao Z, Deng D, et al. MicroRNA-224 sustains Wnt/ beta-catenin signaling and promotes aggressive phenotype of colorectal cancer. J Exp Clin Cancer Res. 2016;35:21.
83. Zhang JX, Mai SJ, Huang XX, Wang FW, Liao YJ, Lin MC, et al. MiR-29C mediates epithelial-to-mesenchymal transition in human colorectal carcinoma metastasis via PTP4A and GNA13 regulation of beta-catenin signaling. Ann Oncol. 2014;25:2196-204.

84. Wang B, Li W, Liu H, Yang L, Liao Q, Cui S, et al. miR-29b suppresses tumor growth and metastasis in colorectal cancer via downregulating Tiam1 expression and inhibiting epithelial-mesenchymal transition. Cell Death Dis. 2014;5:e1335.

85. Tang W, Zhu Y, Gao J, Fu J, Liu C, Liu Y, et al. MicroRNA-29a promotes colorectal cancer metastasis by regulating matrix metalloproteinase 2 and E-cadherin via KLF4. Br J Cancer. 2014;110:450-8.

86. Korpal M, Lee ES, Hu G, Kang Y. The miR-200 family inhibits epithelialmesenchymal transition and cancer cell migration by direct targeting of $\mathrm{E}$ cadherin transcriptional repressors ZEB1 and ZEB2. J Biol Chem. 2008;283: 14910-4.

87. Park SM, Gaur AB, Lengyel E, Peter ME. The miR-200 family determines the epithelial phenotype of cancer cells by targeting the E-cadherin repressors ZEB1 and ZEB2. Genes Dev. 2008;22:894-907.

88. Chen ML, Liang LS, Wang XK. miR-200c inhibits invasion and migration in human colon cancer cells SW480/620 by targeting ZEB1. Clin Exp Metastasis. 2012;29:457-69.

89. Hur K, Toiyama Y, Takahashi M, Balaguer F, Nagasaka T, Koike J, et al. MicroRNA-200c modulates epithelial-to-mesenchymal transition (EMT) in human colorectal cancer metastasis. Gut. 2013;62:1315-26.

90. Sun Y, Shen S, Liu X, Tang H, Wang Z, Yu Z, et al. MiR-429 inhibits cells growth and invasion and regulates EMT-related marker genes by targeting Onecut2 in colorectal carcinoma. Mol Cell Biochem. 2014; 390:19-30.

91. Zheng YB, Luo HP, Shi Q, Hao ZN, Ding Y, Wang QS, et al. miR-132 inhibits colorectal cancer invasion and metastasis via directly targeting ZEB2. World J Gastroenterol. 2014;20:6515-22.

92. Geng L, Chaudhuri A, Talmon G, Wisecarver JL, Are C, Brattain M, et al, MicroRNA-192 suppresses liver metastasis of colon cancer. Oncogene. 2014; 33:5332-40.

93. Sun Z, Zhang Z, Liu Z, Qiu B, Liu K, Dong G. MicroRNA-335 inhibits invasion and metastasis of colorectal cancer by targeting ZEB2. Med Oncol. 2014;31:982.

94. Hahn S, Jackstadt R, Siemens H, Hunten S, Hermeking H. SNAIL and miR-34a feed-forward regulation of ZNF281/ZBP99 promotes epithelial-mesenchymal transition. EMBO J. 2013;32:3079-95.

95. Rokavec M, Oner MG, Li H, Jackstadt R, Jiang L, Lodygin D, et al. IL-6R/ STAT3/miR-34a feedback loop promotes EMT-mediated colorectal cancer invasion and metastasis. J Clin Invest. 2014;124:1853-67.

96. Chen DL, Wang ZQ, Zeng ZL, Wu WJ, Zhang DS, Luo HY, et al. Identification of microRNA-214 as a negative regulator of colorectal cancer liver metastasis by way of regulation of fibroblast growth factor receptor 1 expression. Hepatology. 2014;60:598-609.

97. Loo JM, Scherl A, Nguyen A, Man FY, Weinberg E, Zeng Z, et al. Extracellular metabolic energetics can promote cancer progression. Cell. 2015;160:393-406.

98. Feng $Y$, Zhu J, Ou C, Deng Z, Chen M, Huang W, et al. MicroRNA-145 inhibits tumour growth and metastasis in colorectal cancer by targeting fascin-1. Br J Cancer. 2014:110:2300-9.

99. Yuan W, Sui C, Liu Q, Tang W, An H, Ma J. Up-regulation of microRNA-145 associates with lymph node metastasis in colorectal cancer. PLoS One. 2014 9:e102017.

100. Zhang GJ, Li JS, Zhou H, Xiao HX, Li Y, Zhou T. MicroRNA-106b promotes colorectal cancer cell migration and invasion by directly targeting DLC1. J Exp Clin Cancer Res. 2015;34:73.

101. Xiong B, Cheng Y, Ma L, Zhang C. MiR-21 regulates biological behavior through the PTEN/PI-3 K/Akt signaling pathway in human colorectal cancer cells. Int J Oncol. 2013:42:219-28.

102. Ke TW, Wei PL, Yeh KT, Chen WT, Cheng YW. MiR-92a promotes cell metastasis of colorectal cancer through PTEN-mediated PI3K AKT pathway. Ann Surg Oncol. 2015;22:2649-55.

103. Zhang G, Zhou H, Xiao H, Liu Z, Tian H, Zhou T. MicroRNA-92a functions as an oncogene in colorectal cancer by targeting PTEN. Dig Dis Sci. 2014:59:98-107.

104. Fang L, Li H, Wang L, Hu J, Jin T, Wang J, et al. MicroRNA-17-5p promotes chemotherapeutic drug resistance and tumour metastasis of colorectal cancer by repressing PTEN expression. Oncotarget. 2014;5:2974-87.

105. Qin J, Luo M. MicroRNA-221 promotes colorectal cancer cell invasion and metastasis by targeting RECK. FEBS Lett. 2014;588:99-104. 
106. Sun K, Wang W, Zeng JJ, Wu CT, Lei ST, Li GX. MicroRNA-221 inhibits CDKN1C/p57 expression in human colorectal carcinoma. Acta Pharmacol Sin. 2011;32:375-84.

107. Liu X, Zhang Z, Sun L, Chai N, Tang S, Jin J, et al. MicroRNA-499-5p promotes cellular invasion and tumor metastasis in colorectal cancer by targeting FOXO4 and PDCD4. Carcinogenesis. 2011;32:1798-805.

108. Yang MH, Yu J, Jiang DM, Li WL, Wang S, Ding YQ. microRNA-182 targets special AT-rich sequence-binding protein 2 to promote colorectal cancer proliferation and metastasis. J Transl Med. 2014;12:109.

109. Wang S, Yang MH, Wang XY, Lin J, Ding YQ. Increased expression of miRNA-182 in colorectal carcinoma: an independent and tissue-specific prognostic factor. Int J Clin Exp Pathol. 2014;7:3498-503.

110. Sakamori R, Das S, Yu S, Feng S, Stypulkowski E, Guan Y, et al. Cdc42 and Rab8a are critical for intestinal stem cell division, survival, and differentiation in mice. J Clin Invest. 2012;122:1052-65.

111. Gomez Del Pulgar T, Valdes-Mora F, Bandres E, Perez-Palacios R, Espina C, Cejas $P$, et al. Cdc42 is highly expressed in colorectal adenocarcinoma and downregulates ID4 through an epigenetic mechanism. Int J Oncol. 2008:33:185-93.

112. Sakamori R, Yu S, Zhang X, Hoffman A, Sun J, Das S, et al. CDC42 inhibition suppresses progression of incipient intestinal tumors. Cancer Res. 2014;74:5480-92.

113. Ke TW, Hsu HL, Wu YH, Chen WT, Cheng YW, Cheng CW. MicroRNA-224 suppresses colorectal cancer cell migration by targeting Cdc42. Dis Markers. 2014;2014:617150.

114. Kim DH, Pickhardt PJ, Taylor AJ, Leung WK, Winter TC, Hinshaw JL, et al. CT colonography versus colonoscopy for the detection of advanced neoplasia. N Engl J Med. 2007;357:1403-12.

115. Levin B, Lieberman DA, McFarland B, Andrews KS, Brooks D, Bond J, et al. Screening and surveillance for the early detection of colorectal cancer and adenomatous polyps, 2008: a joint guideline from the American Cancer Society, the US multi-society task force on colorectal cancer, and the American College of Radiology. Gastroenterology. 2008;134:1570-95.

116. Lieberman DA. Clinical practice. Screening for colorectal cancer. N Engl J Med. 2009;361:1179-87.

117. Bonfrate L, Altomare DF, Di Lena M, Travaglio E, Rotelli MT, De Luca A, et al. MicroRNA in colorectal cancer: new perspectives for diagnosis, prognosis and treatment. J Gastrointestin Liver Dis. 2013;22:311-20.

118. Fesler A, Jiang J, Zhai H, Ju J. Circulating microRNA testing for the early diagnosis and follow-up of colorectal cancer patients. Mol Diagn Ther. 2014;18:303-8.

119. Wang K, Yuan Y, Cho JH, McClarty S, Baxter D, Galas DJ. Comparing the MicroRNA spectrum between serum and plasma. PLoS One. 2012;7:e41561.

120. Ahmed FE, Amed NC, Vos PW, Bonnerup C, Atkins JN, Casey M, et al. Diagnostic microRNA markers to screen for sporadic human colon cancer in blood. Cancer Genomics Proteomics. 2012;9:179-92.

121. Ahmed FE, Jeffries CD, Vos PW, Flake G, Nuovo GJ, Sinar DR, et al. Diagnostic microRNA markers for screening sporadic human colon cancer and active ulcerative colitis in stool and tissue. Cancer Genomics Proteomics. 2009:6:281-95.

122. Fang Z, Tang J, Bai Y, Lin H, You H, Jin H, et al. Plasma levels of microRNA24, microRNA-320a, and microRNA-423-5p are potential biomarkers for colorectal carcinoma. J Exp Clin Cancer Res. 2015;34:86.

123. Chen X, Ba Y, Ma L, Cai X, Yin Y, Wang K, et al. Characterization of microRNAs in serum: a novel class of biomarkers for diagnosis of cancer and other diseases. Cell Res. 2008;18:997-1006.

124. Zheng G, Du L, Yang X, Zhang X, Wang L, Yang Y, et al. Serum microRNA panel as biomarkers for early diagnosis of colorectal adenocarcinoma. $\mathrm{Br} J$ Cancer. 2014;111:1985-92.

125. Ng EK, Chong WW, Jin H, Lam EK, Shin VY, Yu J, et al. Differential expression of microRNAs in plasma of patients with colorectal cancer: a potential marker for colorectal cancer screening. Gut. 2009;58:1375-81.

126. Pu XX, Huang GL, Guo HQ, Guo CC, Li H, Ye S, et al. Circulating miR-221 directly amplified from plasma is a potential diagnostic and prognostic marker of colorectal cancer and is correlated with p53 expression. J Gastroenterol Hepatol. 2010;25:1674-80.

127. Link A, Balaguer F, Shen Y, Nagasaka T, Lozano JJ, Boland CR, et al. Fecal MicroRNAs as novel biomarkers for colon cancer screening. Cancer Epidemiol Biomark Prev. 2010;19:1766-74

128. Li JM, Zhao RH, Li ST, Xie CX, Jiang HH, Ding WJ, et al. Down-regulation of fecal miR-143 and miR-145 as potential markers for colorectal cancer. Saudi Med J. 2012;33:24-9.
129. Wu CW, Ng SS, Dong YJ, Ng SC, Leung WW, Lee CW, et al. Detection of miR-92a and miR-21 in stool samples as potential screening biomarkers for colorectal cancer and polyps. Gut. 2012;61:739-45.

130. Koga Y, Yasunaga M, Takahashi A, Kuroda J, Moriya Y, Akasu T, et al. MicroRNA expression profiling of exfoliated colonocytes isolated from feces for colorectal cancer screening. Cancer Prev Res (Phila). 2010;3: $1435-42$.

131. Hinoi T, Akyol A, Theisen BK, Ferguson DO, Greenson JK, Williams BO, et al. Mouse model of colonic adenoma-carcinoma progression based on somatic Apc inactivation. Cancer Res. 2007;67:9721-30.

132. Valeri N, Braconi C, Gasparini P, Murgia C, Lampis A, Paulus-Hock V, et al. MicroRNA-135b promotes cancer progression by acting as a downstream effector of oncogenic pathways in colon cancer. Cancer Cell. 2014;25:469-83.

133. Wu W, Wang Z, Yang P, Yang J, Liang J, Chen Y, et al. MicroRNA135b regulates metastasis suppressor 1 expression and promotes migration and invasion in colorectal cancer. Mol Cell Biochem. 2014; 388:249-59

134. Oberg AL, French AJ, Sarver AL, Subramanian S, Morlan BW, Riska SM, et al. miRNA expression in colon polyps provides evidence for a multihit model of colon cancer. PLoS One. 2011;6:e20465.

135. Chai H, Liu M, Tian R, Li X, Tang H. miR-20a targets BNIP2 and contributes chemotherapeutic resistance in colorectal adenocarcinoma SW480 and SW620 cell lines. Acta Biochim Biophys Sin. 2011;43:217-25.

136. Wang CJ, Stratmann J, Zhou ZG, Sun XF. Suppression of microRNA-31 increases sensitivity to 5 - FU at an early stage, and affects cell migration and invasion in HCT-116 colon cancer cells. BMC Cancer. 2010;10:616.

137. Valeri N, Gasparini P, Braconi C, Paone A, Lovat F, Fabbri M, et al. MicroRNA21 induces resistance to 5 -fluorouracil by down-regulating human DNA MutS homolog 2 (hMSH2). Proc Natl Acad Sci U S A. 2010;107:21098-103.

138. Huang Z, Huang S, Wang Q, Liang L, Ni S, Wang L, et al. MicroRNA-95 promotes cell proliferation and targets sorting Nexin 1 in human colorectal carcinoma. Cancer Res. 2011;71:2582-9.

139. Tsang WP, Ng EK, Ng SS, Jin H, Yu J, Sung JJ, et al. Oncofetal H19-derived miR-675 regulates tumor suppressor RB in human colorectal cancer. Carcinogenesis. 2010;31:350-8.

140. Jung J, Yeom C, Choi YS, Kim S, Lee E, Park MJ, et al. Simultaneous inhibition of multiple oncogenic miRNAs by a multi-potent microRNA sponge. Oncotarget. 2015;6:20370-87.

141. Choi WY, Giraldez AJ, Schier AF. Target protectors reveal dampening and balancing of Nodal agonist and antagonist by miR-430. Science (New York, NY). 2007;318:271-4.

142. Tripp VT, Young DD. Discovery of small molecule modifiers of microRNAs for the treatment of HCV infection. Methods Mol Biol. 2014; 1103:153-63.

143. Ye J, Wu X, Wu D, Wu P, Ni C, Zhang Z, et al. miRNA-27b targets vascular endothelial growth factor $\mathrm{C}$ to inhibit tumor progression and angiogenesis in colorectal cancer. PLoS One. 2013;8:e60687.

144. Hiraki M, Nishimura J, Takahashi H, Wu X, Takahashi Y, Miyo M, et al. Concurrent Targeting of KRAS and AKT by MiR-4689 Is a Novel Treatment Against Mutant KRAS Colorectal Cancer. Mol Ther-Nucleic Acids. 2015;4:e231.

145. Ng EK, Tsang WP, Ng SS, Jin HC, Yu J, Li JJ, et al. MicroRNA-143 targets DNA methyltransferases 3A in colorectal cancer. Br J Cancer. 2009;101:699-706.

146. Nakagawa Y, linuma M, Naoe T, Nozawa Y, Akao Y. Characterized mechanism of alpha-mangostin-induced cell death: caspase-independent apoptosis with release of endonuclease-G from mitochondria and increased miR-143 expression in human colorectal cancer DLD-1 cells. Bioorg Med Chem. 2007;15:5620-8.

147. Zhang H, Tang J, Li C, Kong J, Wang J, Wu Y, et al. MiR-22 regulates 5-FU sensitivity by inhibiting autophagy and promoting apoptosis in colorectal cancer cells. Cancer Lett. 2015;356:781-90.

148. Borralho PM, Kren BT, Castro RE, da Silva IB, Steer CJ, Rodrigues CM. MicroRNA-143 reduces viability and increases sensitivity to 5-fluorouracil in HCT116 human colorectal cancer cells. FEBS J. 2009;276:6689-700.

149. Deng J, Lei W, Fu JC, Zhang L, Li JH, Xiong JP. Targeting miR-21 enhances the sensitivity of human colon cancer HT-29 cells to chemoradiotherapy in vitro. Biochem Biophys Res Commun. 2014;443:789-95.

150. Li X, Li X, Liao D, Wang X, Wu Z, Nie J, et al. Elevated microRNA-23a expression enhances the chemoresistance of colorectal cancer cells with microsatellite instability to 5 -fluorouracil by directly targeting ABCF1. Curr Protein Pept Sci. 2015;16:301-9. 
151. Zhou Y, Wan G, Spizzo R, Ivan C, Mathur R, Hu X, et al. miR-203 induces oxaliplatin resistance in colorectal cancer cells by negatively regulating ATM kinase. Mol Oncol. 2014;8:83-92.

152. Zhang Y, Zheng L, Huang J, Gao F, Lin X, He L, et al. MiR-124

Radiosensitizes human colorectal cancer cells by targeting PRRX1. PLoS One. 2014;9:e93917.

153. Van Cutsem E, Nordlinger B, Cervantes A. Advanced colorectal cancer: ESMO clinical practice guidelines for treatment. Ann Oncol. 2010;21 Suppl 5:v93-97.

Submit your next manuscript to BioMed Central and we will help you at every step:

- We accept pre-submission inquiries

- Our selector tool helps you to find the most relevant journal

- We provide round the clock customer support

- Convenient online submission

- Thorough peer review

- Inclusion in PubMed and all major indexing services

- Maximum visibility for your research

Submit your manuscript at www.biomedcentral.com/submit 